\title{
Factors influencing dressing performance after stroke
}

\author{
M F Walker, N B Lincoln
}

\begin{abstract}
Sixty consecutive patients with a diagnosis of stroke were assessed using the Nottingham stroke dressing assessment as well as a series of physical and cognitive assessments. Generally the items of clothing worn on the lower half of the body were significantly correlated with the physical assessments and the items of clothing worn on the upper half were significantly correlated with the cognitive assessments. These results support other studies which suggest that motor recovery and perceptual abilities are important determinants of dressing ability.
\end{abstract}

Occupational therapists working with stroke patients spend a large proportion of their day engaged in teaching patients how to put on and take off items of clothing. Despite such input, however, many are still unable to dress independently several weeks after admission to hospital. This problem was highlighted by Edmans and Lincoln, ${ }^{1}$ who found that from a group of 150 stroke patients admitted consecutively to hospital, $41 \%$ could not dress at one month after stroke.

Tsai, Howe and Lien $^{2}$ noted that some patients "seemed to be unable to achieve the independence of basic dressing skills even though they have adequate balance, strength, motivation and cognition." Previous studies have also indicated that patients with perceptual difficulties are more likely to be dependent for dressing than those without. This was endorsed by both Williams ${ }^{3}$ and Warren ${ }^{4}$ who found a positive correlation between copying ability and dressing activities in hemiplegia. These studies, however, only looked at upper extremity dressing. From previous published research $^{5-7}$ it appears that certain aspects of the dressing process have been documented after stroke but none has attempted to look at all the components of dressing or identify which stages are particularly difficult.

To identify dressing problems a standardised assessment for stroke patients was developed. Although occupational therapists frequently use dressing checklists to indicate a patients level of independence, these lists do not break down dressing into its component parts and are a crude form of measurement. As there was no published scorable assessment to accurately record this information, the Nottingham stroke dressing assessment was developed. ${ }^{8}$ This detailed assessment enabled us to document the stages in dressing that caused the most difficulty.

The aim of this study was to investigate the relationship between dressing abilities, as identified on the Nottingham stroke dressing assessment, and cognitive and physical problems.

\section{Method}

\section{Patient selection}

All patients were seen on the Stroke Unit at Nottingham General Hospital. Patients are admitted to the Stroke Unit by referral from the two main city hospitals in Nottingham. Referrals are made as early as possible, when the patient is medically stable and the consultant is of the opinion that the patient shows the potential to improve with intensive rehabilitation. An average of 60 patients are treated annually.

Patients were excluded if they had a previous history of dementia, epilepsy or had received cerebral surgery since the onset of their stroke. Patients were also excluded if they did not speak or understand English before their stroke as they would not be able to complete all the cognitive assessments. Over a twelve month period, 60 consecutive patients with a diagnosis of stroke were eligible to take part in the study.

\section{Procedure}

The patients' dressing abilities were recorded on the Nottingham stroke dressing assessment within seven days of admission to the stroke unit. A separate assessment is used for males and females with a maximum of 38 and 58 stages respectively. The patient's level of independence is assessed on each item of clothing using a three tier scoring system; $0=$ dependent, $1=$ dependent with verbal assistance only, $2=$ independent. Therefore each patient's maximum score may be different depending on the type and number of garments they wear. One occupational therapist documented the dressing abilities of all patients, only intervening to give verbal advice or to put clothes on for dependent patients. As each stage of dressing was achieved the assessor scored accordingly, therefore no extra time was required to complete the assessment. During the first week after admission patients were also assessed on a series of physical and cognitive assessments. Standardised assessments were used when available. Each patient was assessed on the following:

1 Rivermead Motor Function Assessment.9

and in revised form

Accepted 25 January 1991 
This is subdivided into three scales: Gross function, Leg and Trunk, and Arm.

2 Rivermead Activities of Daily Living Scale (self care section $)^{10}-\mathrm{a} 16$ point self care scale including feeding, washing, dressing and mobility.

3 Perceptual abilities-Rivermead Perceptual Assessment Battery ${ }^{11}$. This is a validated test containing 16 subtests. Each subtest was considered for analysis as was a total score.

4 Language abilities-Frenchay Aphasia Screening Test ${ }^{12}$-this test covers the four main aspects of language: comprehension, expression, reading and writing.

5 Memory function-Logical memory, subtest of Wechsler Memory Scale ${ }^{13}$ immediate recall and half hour delayed recall and Recognition Memory test Words and Faces. ${ }^{14}$

6 Level of cognitive functioning-National Adult Reading Test (NART) $)^{15}$ and Coloured Progressive Matrices. ${ }^{16}$

7 Sensory assessment-an unpublished test covering eleven aspects of sensation.

8 Apraxia-subtest of the Western Aphasia Battery. ${ }^{17}$

9 Reasoning ability-What's in a square?Board game. ${ }^{18}$

10 Coordination-Pursuit Rotor-assessment of hand eye coordination.

\section{Results}

Subjects

In the 12 months from November 1987 to October 1988 there were 62 patients admitted to the Stroke Unit. Of these admissions two were excluded. One woman had received surgery for an aneurysm resulting in hemiplegia and blindness in one eye and one man did not understand English before his stroke. Included in the study were 37 male patients and 23 female patients. Patients were aged between 21 and 79 years, mean (SD) age $62 \cdot 4$ years, $(9 \cdot 5)$. Of these patients 28 had had a left hemiplegia, $30 \mathrm{a}$ right hemiplegia, one a bilateral stroke and one a brainstem stroke. Time since onset of stroke ranged from two weeks to twelve weeks, mean (SD) time 4.5 weeks, $(2 \cdot 0)$.

Table Relation between physical and cognitive abilities and overall dressing score

\begin{tabular}{|c|c|c|}
\hline Ability assessed & $r$ & $p$ \\
\hline $\begin{array}{l}\text { Activities of daily living } \\
\text { Gross function } \\
\text { Leg } \\
\text { Arm } \\
\text { Pursuit rotor } \\
\text { Coloured progressive matrices } \\
\text { Frenchay aphasia screening test } \\
\text { Rivermead perceptual assessment battery } \\
\text { Total score } \\
\text { Sensory assessment } \\
\text { Total score } \\
\text { Wechsler memory scale } \\
\text { Immediate recall } \\
\text { Half hour delay } \\
\text { Recognition memory test faces } \\
\text { Recognition memory test words } \\
\text { National adult reading test } \\
\text { Apraxia } \\
\text { What's in a square? }\end{array}$ & $\begin{array}{r}0.56 \\
0.67 \\
0.56 \\
0.29 \\
0.36 \\
0.27 \\
0.22 \\
\\
0.25 \\
\\
0.33 \\
\\
0 \cdot 15 \\
-0.05 \\
0.19 \\
0.21 \\
0.14 \\
0.01 \\
0.11\end{array}$ & $\begin{array}{l}\star \star \star \\
\star \star \star \\
\star \star \star \\
\star \\
\star \star \\
\star \\
\star \\
\star \\
\star \\
\text { NS } \\
\text { NS } \\
\text { NS } \\
\text { NS } \\
\text { NS } \\
\text { NS } \\
\text { NS }\end{array}$ \\
\hline
\end{tabular}

Analysis of results

To obtain an overall score for dressing and allowing for garment variation, a percentage score of independence was formulated. Dressing score ranged from $5-100 \%$, mean (SD) score 64.9 (23.4). This score was then correlated with all other physical and cognitive assessments using a Spearman Rank Correlation Coefficient. The table illustrates the significant correlations. This shows that out of the 16 abilities assessed, nine were significantly correlated with dressing ability.

As dressing ability is thought to be related to perceptual abilities each subtest of the Rivermead Perceptual Battery Assessment was correlated with overall dressing score using the Spearman Rank Correlation Coefficient. This indicated that 10 of the 16 subtest scores were significantly correlated with dressing ability. Similarly all areas of sensation were correlated in this manner. Results indicated a significant correlation for six of the 10 subtests. The effect of side of stroke and sex were investigated using a Mann-Whitney "U" test which showed no significant difference between patients with right hemiplegia and left hemiplegia $(\mathrm{U}=340.0 \mathrm{p}>0.05)$ or male and female patients $(U=328.0 \mathrm{p}>0.05)$.

To investigate the effect of physical and cognitive abilities on specific stages of the dressing process the most difficult aspects of dressing were identified. The frequency of problems in dressing were determined using the SPSS-X statistical package. ${ }^{8}$ In both male and female assessments pulling up trousers, putting shoe on the affected foot, lacing shoes and pulling pants up were the most difficult stages in the dressing process. As the scoring system used in the dressing assessment was a three point scale, a Spearman Rank Correlation Coefficient was used to correlate each of the 58 stages of dressing with the physical and cognitive assessments that had been demonstrated to be significantly correlated with dressing ability. Of the significant correlations, 23 were significant at the level of $p<0.001,28$ were significant at the level of $p<0.01$ and 51 were significant at the level of $p<0.05$. Generally the items of clothing worn on the lower half of the body were significantly correlated with the physical assessments and the items of clothing worn on the upper half were significantly correlated with the cognitive assessments.

\section{Discussion}

The problems that influence dressing performance vary according to the items of clothing worn, but dressing as a global skill has been demonstrated to be heavily dependent on the physical abilities of stroke patients. This confirms the observation of Mulley ${ }^{19}$ who stated "In practice, dressing difficulty is usually because of physical difficulties - or lack of confidence." This is true of patients who have difficulty putting on garments on the lower half of their body. Dressing ability was most closely associated with performance on tasks requiring visual matching and spatial abilities and a cancellation task designed to measure visual 
inattention. The perceptual deficits which showed highest correlation with dressing ability were on tasks requiring visual matching, spatial abilities and a cancellation task designed to measure visual inattention. There was no significant relation between dressing and written copying taks, which is in direct contrast to results reported by others. ${ }^{34}$

Kinaesthetic sensation was related to dressing ability but light touch, temperature, pain and pressure were not. It seems that it is particularly important in dressing, for patients to know where their limbs are in space but their ability to feel the garments is, however, less important.

As a result of the relationship between perceptual impairment and problems with dressing, many occupational therapists attempt to treat perceptual problems in the hope of improving functional abilities. Results of some studies, however, have failed to show any beneficial effect of practice on perceptual tasks. $^{2021}$ If, as it seems, perceptual practice does not improve perceptual abilities, then there is unlikely to be any effect on dressing skills. It would therefore seem more appropriate that the functional problems were treated directly. Although certain procedures are used routinely by occupational therapists they have not been systematically documented on the basis of the problem identified or the physical and cognitive deficits. Further research is required to investigate the strategies used to overcome dressing problems, so that patients need not undergo lengthy trial and error procedures.

There is debate over the most appropriate time to start dressing practice. Some therapists feel dressing practice should start when the patient is medically stable while others believe it is detrimental to start before sitting balance has been established. Although patients benefit from dressing practice at an early stage in recovery, they may be more receptive to treatment after discharge from hospital when their personal aims of independence in walking and discharge to home have been achieved.

Dressing apraxia is often quoted when discussing problems encountered by stroke patients. It is therefore surprising that apraxia as defined by Hecaen ${ }^{22}$ was not significantly correlated with overall independence in dressing or with any of the individual stages of dressing. However, despite $25 \%$ of patients included in this study identified as having significant apraxic difficulties, the ability of a stroke patient to dress is heavily overshadowed by their physical abilities.

We thank Trent Regional Health Authority for financial support, Mrs A Dudley for clerical assistance and the stroke patients who generously participated in this study.

1 Edmans JE, Lincoln NB. The frequency of perceptua deficits after stroke. Clin Rehab 1987;1:273-81.

2 Tsai L, Howe T, Lien I. Visuospatial deficits in stroke patients and their relationship to dressing performance. J Formosan Med Assoc 1983;82:353-9.

3 Williams N. Correlation between copying ability and dressing activities in hemiplegia. Am J Phys Med 1967;46(4): $1332-40$

4 Warren M. Relationship of constructional apraxia and body scheme disorders to dressing performance in adult CVA Am J Occ Therapy 1981;35(7):431-7.

5 Bernspang B, Asplund K, Eriksson S, Fugl-Meyer AR. Motor and perceptual impairments in acute stroke patients: effects on self-care ability. Stroke 1987;18: No 6 Nov-Dec 1987.

6 Dudgeon BJ, DeLisa JA, Miller RM. Optokinetic Nystagmus and upper extremity dressing independence after stroke. Arch Phys Med Rehab 1985;66:164-7.

7 Lorenze EJ, Cancro R. Dysfunction in Visual Perception with Hemiplegia: Its relation to activities of daily living. with Hemiplegia: Its relation to activitie
Arch Phys Med Rehab 1962;43:514-7.

8 Walker MF, Lincoln NB. Reaquisition of dressing skills after stroke. Int Disabil Studies (in press)

9 Lincoln NB, Leadbitter D. Assessment of Motor Function in stroke patients. Physiotherapy 1979;65:(2)48-51.

10 Whiting SE, Lincoln NB. An ADL assessment for stroke patients. Br J Occ Therapy 1980;2:44-6.

11 Whiting SE, Lincoln NB, Cockburn J, Bhavani G. The Rivermead Perceptual Assessment Battery. Windsor: NFER-Nelson, 1985.

12 Enderby PM, Wood VA, Wade DT, Langton-Hewer R The Frenchay Aphasia Screening Test: a short, simple test for aphasia appropriate for non-specialists. Int Rehab Med 1987;8:166-70.

13 Wechsler D. A standardised memory scale for clinical use. J Psychol 1945;19:87-95.

14 Warrington EK. Recognition Memory Test. Windsor: NFER-Nelson, 1984 .

15 Nelson HE, Warrington EK. The National Adult Reading Test. Windsor: NFER-Nelson, 1983.

16 Raven JC. Guide to using the Coloured Progressive Matrices. London: Lewis, 1958.

7 Kertesz A, Ferro JM. Lesion size and location in ideomoto apraxia. Brain 1984;107:921-33.

18 Arnold EJ Ltd. What's in a square? Lockwood Distribution Centre, Leeds.

19 Mulley GP. Practical management of stroke. Croom Helm London and Sydney, 1985.

20 Edmans JA, Lincoln NB. Treatment of visual perceptua deficits after stroke: four single case studies. Int Disabil deficits after stroke: four
Studies 1989;11:25-33.

21 Robertson IH, Gray JM, Pentland B, Waite L. A randomised controlled trial of microcomputer-based rehabilitation for unilateral visual neglect. Arch Phys Med Rehab (in press)

22 Hecaen H. Apraxias. The handbook of clinical neuropsychology. New York: John Wiley, 1981 